\title{
O vazio da cidade e os afetos dos lugares em Poema sujo de Ferreira Gullar
} The emptiness of the city and the affections for places in Poema sujo, by Ferreira Gullar

Doutora em Teoria Literária. Professora dos Programas de Pós-Graduacão em Letras da Universidade Estadual do Plaul - UESPI e da Coordenadora do Grupo de Pesquisa Interdisciplinar em Literatura e Linguagem (LITERLI) da UEMA. Desenvolve um Projeto de Pesquisa Universal - sobre memória da cidade em obras de expressão maranhense, financiado pela Agência de

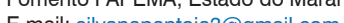

RESUMO: Este trabalho propõe analisar a relação entre homem e cidade com ênfase nos espaços de referência na obra Poema sujo, de Ferreira Gullar. Para tanto, levamos em conta a distância temporal entre o contexto da cidade provinciana, das vivências do sujeito poético e da urbe, remodelada pelo progresso. Nessa conjuntura, a cidade passara a ser marcada pela visão fragmentada e por formas diferentes de convivência: os fios da rede de relações ancorados no espírito coletivo se desprenderam, gerando, no contexto urbano, desenraizamento, perda de referência, individualização e esfacelamento da memória. É nesse contexto de fluidez, de valorização do efêmero, cuja regra é a rapidez e tudo parece descartável, que a cidade se molda. As rupturas se desdobram em desmedidos deslocamentos, lacunas e desamparos.

Palavas-chave: Cidade; Modernidade; Poema sujo.

ABSTRACT: Focusing on spaces of reference, this paper aims at analyzing the relationship between man and city in the work Poema sujo, by Ferreira Gullar. We consider, for this purpose, the temporal distance of the context regarding the provincial city, the experiences of the poetic subject and the metropolis remodeled by progress. At this juncture, the city had been marked by a fragmented vision and different forms of coexistence: the threads of relationships network, anchored in the collective spirit, have been detached, causing, in the urban context, rootlessness, reference loss, individualization and memory shattering. It is in this context of fluidity, valorization of ephemerality, whose rule is speed and everything seems disposable, that the city is shaped. The ruptures unfold in excessive displacements, gaps and helplessness.

Keywords: City; Modernity; Poema sujo.

Um choro aberto sobre a Terra / Em bandos de ais .. Guaiar profético se expande [...] Clamor Ninguém se entende! Um Deus não vem!... Babel! 


\section{Introdução}

cidade é um fenômeno da modernidade, é parte de um mundo distendi-

do que derrocou uma caminhada marcada pela visão fragmentada, por formas diferentes de convivência. A emergência da cidade moderna está relacionada ao mito em torno de Paris, a cidade-luz. Considerada o centro do mundo, Paris passara a ser símbolo da civilização e elegância. 0 processo de modernização da capital francesa foi tomado como modelo, tanto em relação às transformações urbanísticas - ampliação das vias públicas e galerias, quanto à moda e aos costumes.

Fundadas no consumo, as cidades modernas incutiram nos indivíduos a ilusão de que o capitalismo carregaria em seu bojo a promessa de felicidade. Seus dinamismos orientaram o desenvolvimento econômico, proporcionando profundas transformações urbano-sociais: o mundo civilizado surgiu com fábricas fumegando, com a luminosidade dos cafés e com avenidas que comportam passantes acelerados. Na emergência da sociedade parisiense, movida pelo progresso, o homem adotara uma postura padronizada e mecânica, cuja atitude passara a ser guiada pelo comportamento da massa.

A cidade passara a incorporar novas formas de vida, tornando-se movente e descontínua. Bauman (2001, p. 08) diz que "os fluidos se movem facilmente. Mas a modernidade não foi, desde o início, o derretimento dos sólidos?", questiona o sociólogo. Assim, o pensamento impactado pela contingência tem, gradativamente, impulsionado a derrocada de um mundo em que o homem é arremessado a contextos apartados de si.

0 processo irrefreado de modernização levara a vida na cidade à temporalidades fugazes. É a consciência da efemeridade que induz o homem urbano à busca incessante pelo novo. Eis o que configura o modo de vida dos tempos modernos na cidade: a fluidez. 0 homem, na sua ânsia de viver tudo rapidamente, passara a ser movido pelo que é transitório.
Na conferência intitulada A metrópole e a vida mental, em 1903, George Simmel (1987) assevera que a multiplicidade de imagens pulsantes na cidade grande opera diretamente no psiquismo humano, causando-lhe impacto. O homem metropolitano, além de manter um distanciamento em relação ao outro, nutre-se de aversão, estranheza e repulsa recíprocas, denominado por Simmel de reserva, uma espécie de reação psíquica capaz de proteger o homem dos incessantes estímulos visuais e de outros impactos comunicativos da vida moderna. É também vista como defesa contra a violenta transformação da paisagem urbana que, cotidianamente, exige da consciência um desgaste maior. Um apelo intenso aos mecanismos sensoriais denominados de atitude blasé.

Lasch (1986), corroborando com o pensamento de Simmel, assevera que a cultura do consumismo da sociedade pós-industrial é a causadora desse mecanismo de defesa que denomina de estratégia de sobrevivência psíquica, a qual desencadeia uma individualidade narcísica. Na sociedade de consumo, a percepção deixa de recair sobre o bem comum, sobre a vida humanizada, para se concentrar no próprio eu, bem como em imagens que se exibem aos turbilhões em forma de mercadorias, corroborando para o apagamento de fronteiras entre o indivíduo e seu meio. 0 comportamento narcísico implica a subtração de um mundo de sustentação e confiança, para um mundo de imagens oscilantes e deslizantes.

Diante desse quadro, a literatura passa a ser uma das principais testemunhas das mudanças no tecido urbano, bem como no comportamento humano. Já no fim do século XIX, a poesia de Baudelaire situa o homem em vias públicas, cujo olhar vai desvelando elementos que compõem a nova paisagem, um mundo impactado pela mudança: multidão, bulevares, galerias, ao tempo em que se porta como um exímio flâneur: em meio à multidão vai extraindo material para a sua tessitura poética. No âmago da 
efervescência parisiense, o poeta já tem consciência da perda da totalidade pela fragmentação e dispersão.

Essa questão levou-nos a refletir sobre o sintoma da cidade em mutação, cuja dinamicidade tende a arrastar referências e destruir memórias. Em vista disso, propomos analisar a relação homem/cidade em Poema sujo, de Ferreira Gullar, ante o processo de transformação da paisagem urbana.

Poema sujo é uma obra, com mais de um mil versos, que trata das memórias da infância e adolescência do sujeito poético na cidade de São Luís-MA, cidade natal do poeta. Interessa-nos perceber como o eu poético reconhece a cidade e com ela dialoga, ante o fluxo temporal que, aliado ao progresso, imprime transformações no tecido urbano, alterando os espaços de convivência. O maranhense Ferreira Gullar (1930-2016), vencedor do prêmio Camões de literatura (2010) pelo conjunto da sua obra, é poeta, jornalista, crítico de arte, roteirista de TV, dramaturgo e ensaísta. Escreveu Poema sujo no exílio, em Buenos Aires, em 1975, após uma experiência nômade de exílio político que durou seis anos e sete meses.

A representação da cidade na literatura depende do modo como o escritor faz do espaço urbano "um objeto que precisa ser decifrado, uma escritura que precisa ser lida", assevera Ferrara (1988, p. 41). Aquilo que subjaz ao texto-cidade: a cartografia urbana desnuda aspectos históricos e culturais, bem como fatos de vivências particulares e sociais, cujos rastros permanecem em fissuras e curvas do urbano, possíveis de dar ciência da relação que o homem estabelece com a cidade.

O ambiente urbano é um complexo de signos: os formais (a própria forma do objeto construído), os linguísticos (nomes das ruas), os de propaganda (cartazes), os indicadores de direção, os estéticos (os materiais empregados, as características estilísticas de fachadas, jardins, iluminações, etc.), os contextuais (a situação urbana em que se localiza) e os signos usuários (a especificidade dos comportamentos humanos tomados como signos (FERRARA, 1988, p. 45).
Comparada a um livro, a cidade permite a apreensão de seus significados mediante a leitura/o uso de seus elementos, sendo o próprio uso passível de leitura. Os signos urbanos configuram-se como vias de representação simbólica, pautadas em sociabilidades, afetos ou aversões, por isso é capaz de pôr em cena experiências particulares e coletivas.

O registro literário da cidade decorre da leitura dos espaços e de suas formas, cujas singularidades dão testemunho de acontecimentos e do tempo que transcorre. Nessa perspectiva, Poema sujo eclode do cotidiano, das coisas simples; nasce da "rede suja/da bilha na janela/do girassol no saguão", da calçada, da toalha encardida na mesa de jantar, do fio da lâmpada pegajoso, do galo no quintal, das bananas apodrecendo na quitanda.

Em Poema sujo, o sujeito poético gullariano mergulha no tempo e traça a cartografia da cidade provinciana ou a sua fantasmagoria. Da cidade reconstruída com linguagem eclodem cenas interiores do ambiente familiar: os afetos da casa primordial, o aconchego do quintal e da quitanda paterna, cenas que se revezam com outras, exteriores, de onde emerge o bondinho que corta a cidade e conduz o menino a banhos costumeiros no Rio Anil, as ruas antigas com suas ladeiras, antigas fábricas têxteis e as ruínas de casas escancaradas à claridade, cidade protetora que se contrapõe a atual: hipermoderna remodelada pelo progresso.

O mundo de rápidas movências induz o indivíduo a novos modos de convivência, impostos por diferentes fatores de sociabilidades que, gradativamente, empurram as relações interpessoais cada vez mais para longe. Se a realidade exterior não oferece mais proteção, o poeta interiorizase, busca guarida no espaço/tempo do aconchego e proteção na tentativa de (re) constituir os quadros de referência. Então, entendemos que o labor literário é o que melhor expressa essa gestação. 


\section{0 homem e a cidade que o habita em Poema sujo}

Em Cidades invisíveis, de Ítalo Calvino (1990), o viajante Marco Polo descreve ao Imperador dos tártaros, Kublai Khan, singularidades de espaços citadinos visitados, tendo o cuidado de advertir "que jamais se deve confundir uma cidade com o discurso que a descreve" (p. 59), no entanto para descrevê-la é preciso apropriar-se de um discurso que seja preenchido com os conteúdos da própria cidade.

Os registros que o artista da palavra faz da cidade resulta das leituras que dela faz, articuladas a sua subjetividade, cujas singularidades são filtradas por suas impressões. As cidades construídas por linguagem são feitas de permanências e rupturas inscritas na própria cidade; de conquistas que se exibem em monumentos; de culturas diversas que se intercambiam; da memória inscrita em seus ângulos, em fachadas de prédios, calçamentos, esquinas, becos, ruas, ladeiras, etc. A cidade também é feita de relatos, de experiências e da banalidade cotidiana.

A cidade, vista por esse prisma, ultrapassa a condição de mera estrutura em pedra e cal, cujo sentido recai sobre si própria, para adquirir valor que se confirma pela medida dos acontecimentos e pela trama das relações humanas.

A cidade-texto metropolitana mostra-se como uma serpente em convulsão que se metamorfoseia devorando tudo e todos, um labirinto de ruas, fios, redes que polui e impede de se enxergar suas peculiaridades.

Bauman (2008) diz que o meio urbano está repleto de espaços que ele intitula de templo de consumo. Cita como exemplo a Praça La Défense, destituída de acolhimento que "desencoraja a permanência", posto que é um espaço extremamente amplo e esvaziado de relações. A referida praça se dá como espetáculo: os bancos estão dispostos a uma certa distância, acima da altura dela, como se apropriados para as pessoas assistirem a cena de transeuntes que se reveza rapidamente. Acrescenta o sociólogo que o comportamento do homem pautado na escolha individual da primeira modernidade - relacionada ao final do século XIX - almejava tão somente "usar sua nova liberdade para encontrar o nicho apropriado e ali se acomodar", ou seja, o desejo era instaurar uma nova remodelação do mundo ou uma realocação, porém a liberdade tomou proporções por demais ousadas, afastando o homem cada vez para longe de qualquer acomodação. Essa nova visão acentuou-se com o crescimento desordenado dos centros urbanos, que acabou arremessando o homem a um mundo estranho a si, um narciso que não é espelho.

A revolução narcísica ou revolução interior da modernidade (LIPOVETSKY, 2005) é um estado de indiferença a acontecimentos exteriores, sobretudo em relação ao trágico, decorrente da banalização de inúmeras catástrofes cotidianas que, irremediavelmente, presenciamos. Acrescenta:

O narcisismo foi gerado pela deserção generalizada de valores e finalidades sociais, ocasionada pelo processo de personalização. A anulação dos grandes sistemas de sentidos e o hiperinvestimento no Eu andam de braços dados. [...] É a revolução das necessidades e sua ética hedonista que, atomizando suavemente os indivíduos e esvaziando aos poucos as afinidades sociais de seus significados profundos, permitiu que o discurso psíquico enxertasse no social e se tornasse um novo éthos de massa (LIPOVETSKY, 2005, p. 34-35).

Levando em conta esse raciocínio, a cidade não é civil na perspectiva do exercício de civilidades devido ao esvaziamento de finalidades sociais, o que contribui para intensificar o processo de personalização.

Em contrapartida, o uso e funcionalidade da cidade dinamizam os espaços e, invariavelmente, induz a apreensão de seus sentidos pelos habitantes do lugar, cuja pragmática os leva a redescobri-la e a se reconhecer como partícipes da conjuntura à qual pertencem. Assim, o homem vai 
reelaborando informações e vivências em confronto com novas experiências, de modo a ressignificar suas impressões sobre a cidade.

Pesavento (2002, p. 16) diz que os "traçados de ruas e praças são, sem dúvida, o registro físico de uma cidade e também são modos de pensar sua linguagem. Portanto, o espaço é sempre portador de um significado, cuja expressão passa por outras formas de comunicação". Desse modo, a linguagem da cidade possibilita leituras que vão ao encontro dos afetos construídos na convivência, atenuando o vazio de finalidades sociais em meio ao magma urbano.

Ante o exposto, o sujeito lírico de Poema sujo desnuda as tramas da vida em espaços de referências individuais e coletivas da São Luís provinciana - esfacelados pelo tempo e pelo progresso - a partir de um tempo e lugar distanciados, o que possibilita pensar sobre a dinamicidade urbana e seus impactos sobre a subjetividade do eu que se enuncia.

$\mathrm{O}$ desenvolvimento chegou meio trôpego à capital maranhense. No fim do século XIX, a economia da cidade girava em torno do algodão, o que motivou empresários a importar maquinários obsoletos da Inglaterra, para atender à economia têxtil recém implantada na capital. O engenheiro Rui Mesquita, citado por Valdenira Barros, em Imagens do moderno em São Luís, afirma que

Desde a época da fundação, a expansão urbana de São Luís poderia ser agrupada em três diferentes fases: formação do núcleo urbano (séc. XVII, cerca de 10.000 habitantes), constituição do bairro central atual (séc. XVIII e início do século XIX, com aproximadamente 17.000 habitantes), formação dos arrabaldes e bairros excêntricos (séc. XIX e séc. XX, entre 20.000 e 70.000 habitantes) (2001, p. 30).

Na década de 30 do século XX, a capital maranhense ainda permanecia imersa em um estado de subtração em relação às grandes capitais do país. Apesar da morosidade, São Luís não ficou imune aos projetos reformistas.
Assim como outras capitais brasileiras, almejava integrar a imagem do país ao utópico e global sonho de progresso, alimentado pelas exigências do capitalismo. Para se enquadrar na condição de cidade moderna, São Luís arrastou consigo formas arquitetônicas seculares que guardavam referências, histórias e memórias, como é o caso da Igreja de Nossa Senhora dos Mulatos, com arquitetura do século XIX, demolida em 1939, com alegação do grande número de acidentes ocorridos no local, em função do trilho da linha do bonde elétrico que passava muito próximo da lateral da igreja.

Em Poema sujo, desdobram-se procedimentos poéticos que põem em cena um sujeito que se situa, no plano memorialístico, no contexto da década de 30 e 40, época da infância e adolescência do poeta, para repensar a cidade e suas vivências particulares. 0 tempo pretérito se sobrepõe ao presente. Em muitas passagens, a voz poética faz emergir o menino que fora, "meu coração de menino", em detrimento do adulto que é.

A imagem ressoa e repercute na voz de si próprio, em um tempo distante. A gestação da imagem é justamente o jogo em que elementos ultrapassam o funil da memória, por isso a palavra se ajusta para tentar expressar, ao máximo, a imagem que ressoa. Surge, então, o menino a correr livre entre mangues, praias, ladeiras e quintas com dimensão infinita; a pegar pássaros "com alçapão no capinzal"; a retornar de pescarias e de banhos no "Rio Azul"; a se deliciar furtivamente na mesa de bilhar na companhia de amigos.

A memória emotiva é perpassada pela percepção que, por sua vez, acomoda-se no corpo, bem como em significados contidos na face das coisas. O corpo registra o que percebe, o que deseja e, também, o que lhe escapa; logo, detém os componentes emocionais e memorialísticos por meio das marcas de vida e morte, lembrança e esquecimento. Gullar dá voz ao próprio corpo para falar de si e da cidade. 
$[\ldots]$

$$
\begin{aligned}
& \text { Mas sobretudo meu } \\
& \text { nordestino } \\
& \text { mas que isso } \\
& \text { maranhense } \\
& \text { mas que isso } \\
& \text { sanluisense } \\
& \text { mas que isso } \\
& \text { ferreirense } \\
& \text { newtoniense } \\
& \text { alzirense } \\
& \text { [... (GULLAR, 2004, p. 22). }
\end{aligned}
$$

Tomando distância do próprio corpo, o sujeito poético oferece a si um outro corpo que pulsa em uma outra dimensão: no contexto familiar: o Nordeste, seu Estado, sua cidade, o sobrenome paterno, o pai e a mãe. 0 corpo é, então, um espaço que se desdobra e se mostra às avessas, passando a ser ponte e limite entre o cruzamento do próprio eu: ao tempo em que olha ao redor de si, é dotado de capacidade para também olhar para dentro de si, reconhecendo o outro lado, por meio de sua própria interioridade. Assim, o lado de dentro tem uma face e um dorso, cuja dimensão abriga os componentes do passado que não cessam.

A corporeidade delimita a visão e a direciona para lá, onde moram os afetos, logo o passado torna-se presente, ainda que o corpo tenha mudado de forma e de lugar.

$$
[\ldots]
$$

Meu corpo nascido numa porta-e-janela da Rua dos Prazeres Ao lado de uma padaria

Sob o signo de Virgo

Sob as balas do $24 \mathrm{BC}$

Na revolução de trinta

E que desde então segue pulsando como um relógio

[...] (GULLAR, 2004, p. 240).
O corpo recupera as necessidades afetivas, posto que é uma esfera em que ele próprio manifesta os acontecimentos. Em Poema sujo, o corpo se desloca do interior da casa paterna, para o quintal, expande-se para outros quintais até diluir-se no corpo da cidade, ressoando a relação entre o homem e o corpo da cidade que o habita.

\section{$[\ldots]$}

Ah, minha cidade verde

Minha úmida cidade

Constantemente batida de muitos ventos

Rumorejando teus dias à entrada do mar

Minha cidade sonora

Esfera de ventania

Rolando louca por cima dos mirantes

E dos campos de futebol

Verdes verdes verdes verdes

Ah sombra rumorejando

[...] (GULLAR, 2004, p. 275).

Que arrasto por outras ruas

Em Poema sujo, a cidade está ligada à condição de existência do eu lírico, sendo este acometido por um sentimento de posse: "minha cidade", cuja memória é guiada por estímulos visuais, táteis, sonoros, olfativos e sensações sinestésicas que perpassam o corpo, inundando pele, músculos e artérias.

Os apelos sensoriais são atribuídos à cidade a partir de um único vetor: o mar, sentido pelo tato, cuja umidade o envolve; pela audição, imagem aproximada a uma serena orquestração provocada pelos vocábulos "sonora", "ventania" e "rumorejando"; pela visão, ao atribuir à cidade a cor verde, que tinge o mar, que contorna a cidade e que inunda o ser. Desse modo, entre o sujeito poético e a cidade coabitam mistérios que não convêm questioná-los, nem procurar desvendá-los.

Bachelard (1993, p. 104) afirma que a relação homem/cidade assemelhase à do pássaro com o ninho: são vínculos de vida e morte, por isso o homem 
a habita como "refúgio absoluto". Se o pássaro faz o ninho aparentemente em um ambiente frágil, é porque tem o instinto de confiança, acrescenta Bachelard. Na poética gullariana, o sujeito reconstrói sua cidade sob o impulso da confiança e nela fecha-se sobre si próprio, encolhe-se, entoca-se e a habita como refúgio absoluto. Assim, "a cidade está no homem/quase como a árvore voa/no pássaro que a deixa”, diz Gullar (2004, p. 290-291).

Outros espaços sugerem proteção na poética de Gullar, como a "quitanda ninho", lugar de trabalho da figura paterna, que apresenta a "mesma imobilidade branca/do fubá dentro do depósito" (p. 270), cuja dimensão infinita transmite repouso, calmaria, ainda que tais espaços estejam "para sempre riscados do presente doravante estranhos a todas as promessas de futuro" (BACHELARD, 1993, p. 29).

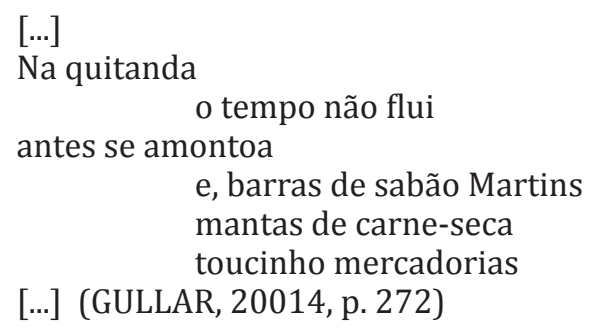

Em meio à dupla passado/presente, a memória busca mecanismos de defesa contra o turbilhão da cidade moderna que arrasta e dissipa os espaços de vivência. No ninho, a vida começa girando sobre si mesma e depois se abre ao espaço ilimitado. Quitanda ninho remete a esse lugar pleno, espaço psíquico de onde saímos e para onde, inconscientemente, desejamos regressar. O ninho é, então, a marca simbólica do retorno. O ninho é o lugar próprio para o "encolhimento", diz Bachelard (1993). E acrescenta: "só mora com intensidade aquele que já soube encolher-se".

Outros espaços entram na categoria dos lugares fechados: "armários obsoletos gavetas perfumadas do passado" (GULLAR, 2004, p. 236) des- dobram-se por entre camadas, cascas, carnaduras e espaços que remetem à vida que começa pulsante sob um invólucro.

Na poética de Gullar, repousa o desejo de manter a cidade com o mesmo gosto das "[...] pastilhas/ de hortelã enroladas em papel de seda coloridas" (GULLAR, 2004, p. 289), que permita que os movimentos do sujeito sejam leves e tentaculares, cujas lembranças sejam capazes de rebobinar a vida. "Ah, ventos soprando verdes nas palmeiras dos Remédios” (GULLAR, 2004, p. 245), largo que acolhe palmeiras à entrada do mar na cidade de São Luís do Maranhão.

Marco Polo, de Calvino (1990, p. 14), tem consciência de que seria inviável descrever as ruas, os formatos das escadas e as "circunferências dos arcos dos pórticos, de quais lâminas de zincos são recobertos os tetos", sem conhecer a história de seus habitantes, porque a cidade não é feita de seus artefatos, mas "das relações entre as medidas de seus espaços e os acontecimentos do passado".

Em Gullar, a cidade vai adquirindo contornos aéreos, moldados pelo vento: cidade, [...] esfera de ventania (GULLAR, p. 275). Vendo sob essa perspectiva, o aéreo implica uma visão panorâmica que favorece o esmagamento dos detalhes e a destruição de nuances, intimidades e afinidades.

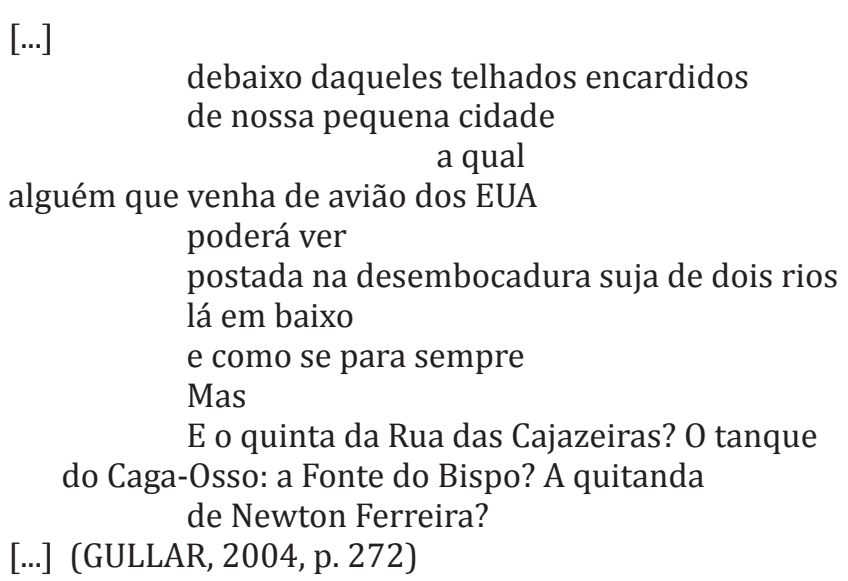


A visão panorâmica coloca o observador fora e acima da cena visualizada. A visão do alto dá a impressão de total horizontalidade, como se a cidade fosse um todo homogêneo. Ao introjetar a conjunção mas, o sujeito poético desautoriza o passageiro aéreo do contato com espaços singulares: um quintal, um tanque, uma fonte, uma rua, uma quitanda, espaços familiares àquele que com eles mantém vínculos afetivos.

O sujeito lírico, ao percorrer a cidade "amontoada de sobrados e mirantes/Ladeiras quintais quitandas" (GULLAR, 20024, p. 244), os becos e as ruas antigas, não se mostra indiferente às transformações da paisagem citadina. A cidade tem muitas velocidades "[...] E em meio a um outro sistema/ este/de ventos" (GULLAR, 2004, p. 271), o eu poético percebe que a cidade tem muitos desdobramentos, que não são lentos como o ritmo das lembranças.

Massey (2012) explica que o lugar, mesmo sendo considerado porto seguro, que abriga as referências, não se exime de acolher distintas trajetórias, isso porque:

As especificidades dos espaços são um produto de inter-relações conexões e desconexões - e seus efeitos (combinatórios). Numa sociedade nem lugares são vistos como tendo qualquer autenticidade atemporal. Eles são e sempre foram interconectados e dinâmicos (MASSEY, 2012, p. 29).

Assim, o reconhecimento da coetaneidade espacial retira-lhe o caráter eurocêntrico e abre para uma multiplicidade de vozes e de outras trajetórias. Nas metrópoles, as ruas são espaços físico-geográficos que estabelecem com os habitantes relações comerciais e políticas. Delas emanam um sistema de signos e de linguagens que orienta deslocamentos e restringe sociabilidades; porém, das ruas de Gullar subjaz uma relação estreita. São como estojos que guardam referências e lembranças, cujos nomes corroboram para ativar a identidade do eu poético.

\section{$[\ldots]$}

na rua da Palma me conheço

na do Alecrim me perfumo

na do Desterro me encontro

na da Alegria me perco

na Rua Direita erro

e na da Aurora adormeço.

[...] (GULLAR, 2004, p. 278)

De forma irreverente, o eu lírico vai reconstruindo o traçado de ruas antigas da cidade, de modo a fundir-se com seus trajetos pessoais. Mais que isso, o corpo se recorta em camadas e se fragmenta no corpo da cidade.

Ao retomar antigos nomes de ruas da cidade de São Luís, subjaz na poética gullariana um desejo de manter vivos aqueles nomes consolidados no imaginário coletivo, cujo sentido concentra-se em evitar que topônimos se percam e se diluam em meio a antropônimos, comuns nas práticas metropolitanas ${ }^{1}$.

As antigas ruas que outrora davam guarida aos seus habitantes, transformaram-se em lugares de passagem e circulação, cujo contato tem a duração do desejo. Na concepção de Augé (1994, p. 95), nos lugares de passagem os indivíduos estão imersos na homogeneidade, já que "o espaço do não lugar não cria nem identidade singular sem relação, mas sim solidão e similitude".

Corroborando com esse pensamento, Bauman (2001, p. 32) diz que nos lugares de passagem o estranho se relaciona com os outros sem perder a sua condição de estranho. Assim, quando os hóspedes vão "seguindo seus próprios itinerários, o lugar fica como era antes de sua chegada, sem ser afetado pelos ocupantes anteriores e esperando por outros no futuro".

${ }^{1}$ Em São Luís, a rua da Paz, da Saúde, das Hortas, dentre outras, foram substituídas por nomes de personalidades locais. 
Nessa perspectiva, o vazio da era moderna não é por completo negativo, mas sim paradoxal: ao tempo em que contempla o nada, tudo se esvai e tudo comporta rapidamente, em um fluxo contínuo de novos significados e de novas comunicações.

A voz poética gullariana, ao se reportar aos antigos bondes, retoma a cartografia da sua cidade e volta a dar visibilidade a nomes de antigas ruas.

[...]

- enquanto o bonde Gonçalves Dias

descia a Rua Rio Branco

rumo à Praça dos Remédios e outros

bondes descia a Rua da Paz

rumo à Praça João Lisboa

e ainda outros rumavam

na direção da Fabril, Apeadouro

Jordão

(esse era o bonde do Anil

que nos levava

para o banho no rio Azul)

[...] (GULLAR, 2004, p. 261)

O que chama atenção aqui é que, dentre os bondes que circundavam a cidade, o sujeito poético destaca aquele que lhe traz lembranças particulares e afinidades: sussurra entre parênteses a singularidade - o bonde que conduzia ao Bairro Anil, que acolhe um patrimônio particular, o Rio Anil, outrora deliciado em banhos costumeiros. Essa particularidade torna ímpar o rio de Gullar. Para que outros rios, como o Tejo, de Fernando Pessoa; o Tietê, de Mário de Andrade se igualassem a seu Rio Anil, seria preciso que fizessem o mesmo percurso: "era preciso que viesse/por esse mesmo caminho [...] para perder-se no mar [...] afogar-se, convulso/nas águas salgadas/da baía"2 (GULLAR, 2004, p. 262) ou que apresentasse as mesmas marcas de degradação.

2 Referência à Baía de São Marcos, em São Luís-MA
As marcas simbólicas que envolvem um rio que apodrece em direção ao Bairro Camboa, e que envolve o "vasto capinzal, [...] para além da estrada de ferro", são representadas em Poema sujo revestidas de consciência crítica e afetiva. Não obstante, para a conjuntura metropolitana, passam a ser escórias que devem ser eliminadas em favor do remodelamento urbano.

O Rio Anil tem seu nascedouro no coração de São Luís. Outrora navegável e vinculado à economia maranhense, passara a ser marcado pela poluição e, aos poucos, vai desaparecendo da contextualização da cidade.

$[\ldots]$

E como nenhum rio apodrece

Do mesmo jeito que outro rio

Assim o rio Anil

Apodrece do seu modo

Naquela parte da ilha de São Luís

[...] (GULLAR, 2004, p. 262)

A imagem do rio está ligada à ideia de deslizamento, passagem temporal que não pode ser apreendida, nem retrocedida. 0 desejo do vir a ser interpõe-se com a imagem da circularidade, a circunferência que parte de um ponto e que para ele converge. Tal circunstância instiga-nos a pensar acerca da noção de instantaneidade, tão cara em tempos hipermodernos.

A instantaneidade (anulação da resistência do espaço e liquefação da materialidade dos objetos) faz com que cada momento pareça ter capacidade infinita significa que não há limites ao que pode ser extraído de qualquer momento - por mais breve e 'fugaz' que seja (BAUMAN 2001, p. 145).

A capacidade infinita, possível na poesia de Gullar, resulta da sua inventividade em condensar no instante, na materialidade do poema, um sentido que se dilata. Expressar essa capacidade, em um tempo infinito, 
é possível graças à consciência crítica sobre as exigências que o contexto moderno impõe.

As mutabilidades dos antigos espaços citadinos, articuladas à verticalidade dos elementos urbanizados das metrópoles, provocam deslocamento das referências do ser na cidade, cujo desenraizamento causa fissuras. A concha do caracol - ser e cidade - não "sai inteira, o que sai contradiz o que fica fechado", assevera Bachelard (1993, p. 120). O que sai fica conectado por uma membrana ao que permanece no interior, de modo que o dilaceramento do lado de fora não compromete a vida de dentro, com isso, a parte interior da condição de pertencimento mantém-se interligada.

\section{Considerações finais}

A cidade moderna emerge com a promessa de que a felicidade está no progresso. A expansão citadina, somada à remodelação de formas urbanas e de modos de vida apressados e fugazes, acaba afastando os sujeitos dos espaços de suas referências individuais e coletivas. Assim, a dinamicidade da urbe leva os indivíduos a reconhecê-la sob novas práticas, geradoras de novos significados, cujos repertórios do passado tonam-se invisibilizados.

Em meio a constantes deslocamentos urbanos, o sujeito metropolitano reage de diferentes formas: como mecanismo de defesa, imerge dentro de si, cujo estado é gerado pela "deserção [...] de finalidades sociais" (LIPOVETESKY, 2005, p. 34). Ante essa realidade, o sujeito poético gullariano ressignifica o vivido, a partir das marcas do ser na cidade. Um sujeito que se recolhe no tempo e faz emergir a São Luís provinciana, com seus espaços de acolhimento, contorcidos, dobrados: a casa paterna, o quintal, a quitanda, as ruas tortuosas, as ladeiras, dentre outros, são espaço que guardam as referências do eu que se enuncia.
Diante da mutabilidade urbana, os espaços não permanecem estáveis. Submerge, então, dos sujeitos sociais um sentido coetâneo: de preservação das referências e também de produção de sentido do Outro, disponível para que diferentes vozes possam descobrir outras formas de acomodação. Ao contrário das estruturas rígidas que priorizavam a homogeneidade, as conexões modernas propõem agenciamentos. Assim, os espaços da urbe metropolitana passam a ser compreendidos como formas que estão ao mesmo tempo interligadas e desestabilizadas, por isso se dão a ver como formas em aberto, em transformação, assim como o tempo e o próprio discurso que as mobiliza. Preso a lembranças, "ao mesmo tempo inserido/ num amplo sistema de velocidades" e de mudanças, o sujeito lírico de Gullar, em Poema Sujo, é consciente de tudo isso, sobretudo de que a vida metropolitana não comporta subjetividades negociáveis, posto que o mundo moderno exige comportamento narcísico.

A consciência poética de Gullar faz com que Poema sujo seja uma forma peculiar de revisitação da cidade natal. Se a retoma, reiteradamente, via memória, é porque a cidade se transformara na imagem do espaço perdido, mas sempre habitado nas lembranças, seja pelo excesso de silêncio ou de barulho, rumores possíveis de favorecer a acomodação do corpo. As marcas mnemônicas testemunham ausência de espaços, incessantemente presentes, com seus nichos, sem necessariamente negar a dinâmica da cidade.

\section{Referências}

AUGÉ, Marc. Não lugares: introdução a uma antropologia da supermodernidade. 8. ed. Tradução Maria Lúcia Pereira. Campinas, SP: Papirus, 1994.

BACHELARD, Gaston. A poética do espaço. Tradução Antonio de Padua Danesi. São Paulo: Martins Fontes, 1993.

BAUMAN, Zigmunt. Modernidade líquida. Tradução Plínio Dentzien. Rio de Janeiro: Jorge Zahar, 2001. 
BARROS, Valdenira. Imagens do moderno em São Luís. São Luís: Stúdio 11, 2001.

CALVInO, Italo. As cidades invisíveis. Tradução Diogo Mainardi. São Paulo: Companhia das Letras, 1990.

GULLAR, Ferreira. Poema sujo. In: Toda poesia. 12. ed. Rio de Janeiro: José Olympio, 2004.

LASCH, Christopher. $O$ mínimo eu: sobrevivência psíquica em tempos difíceis. Tradução João Roberto Martins Filho. São Paulo: Brasiliense, 1986.

LIPOVETESIKY, Gilles. A era do vazio: ensaios sobre individualismo contemporâneo. Tradução Therezinha Monteiro Deutscs. Barueri, SP: Manoele, 2005.

MASSEY, Doreen. Pelo espaço: uma nova política da espacialidade. Tradução Hilda Pareto Maciel; Rogério Haesbaert. 3. ed. Rio de Janeiro: Bertrand Brasil, 2012.

PESAVENTO, Sandra Jatahy. O imaginário da cidade: visões literárias do urbano - Paris, Rio de Janeiro, Porto Alegre. 2. ed. Porto Alegre: Ed. Universidade UFRGS, 2002.

SIMMEL, Georg. A metrópole e a vida mental. In: VELHO, Otávio Guilherme (Org.). o fenômeno urbano. 4. ed. Rio de Janeiro: Guanabara, 1987.

Recebido em 25/01/2017

Aceito em $31 / 10 / 2017$ 